\title{
THE INTERNATIONAL ENERGY WORKSHOP: RESULTS OF THE 1997 POLL
}

Leo Schrattenholzer

International Institute for Applied Systems Analysis

Laxenburg, Austria

RR-98-8

July 1998

Reprinted from OPEC Review, pp. 147-158, June 1998.

International Institute for Applied Systems Analysis, Laxenburg, Austria Tel: +432236807 Fax: +43223673148 E-mail: publications@iiasa.ac.at 
Research Reports, which record research conducted at IIASA, are independently reviewed before publication. Views or opinions expressed herein do not necessarily represent those of the Institute, its National Member Organizations, or other organizations supporting the work.

Reprinted with permission from OPEC Review, pp. 147-158, June 1998.

Copyright (C) 1998 Organization of the Petroleum Exporting Countries.

All rights reserved. No part of this publication may be reproduced or transmitted in any form or by any means, electronic or mechanical, including photocopy, recording, or any information storage or retrieval system, without permission in writing from the copyright holder. 


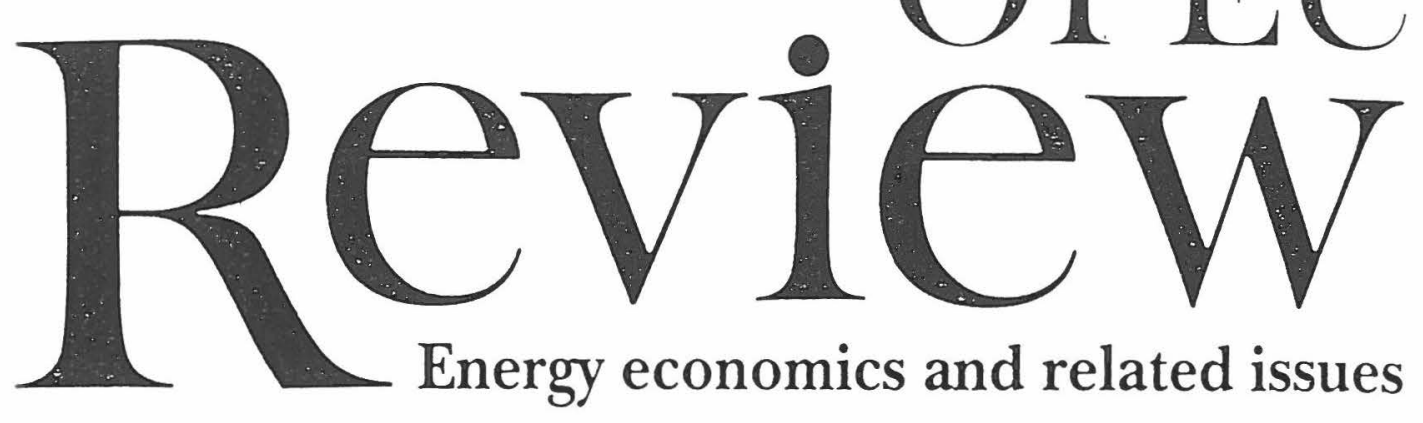

June 1998

\section{The International Energy Workshop: results of the 1997 poll}

by

Leo Schrattenholzer

(c) 1998. Organization of the Pctroleum Exporting Countries

This is a reprint of a paper published in the June 1998 issue of the OPEC Review, which was compiled at the OPEC Secretariat in Vienna. Opinions expressed in the OPEC Revicw are the authors' ow'n and should not be construed as necessarily reflecting the policies or view's of the bodies they represent, or of OPEC.

\section{Organization of the Petroleum Exporting Countries}




\title{
The International Energy Workshop: results of the 1997 poll
}

\section{Leo Schrattenholzer}

\begin{abstract}
$\underline{\text { Abstract }}$
The International Energy Workshop consists of a network of analysts from across the world concerned with international energy issues. Since 1981, the IEW has been organising an annual poll of projections of crude oil prices, economic growth, primary energy consumption and production, the energy trade and, beginning in the early 1990s, energy-related carbon emissions. Submitted projections are for 1990-2020 in ten-year steps; recently, 2050 and 2100 have been added, to cater for climate change scenarios. The IEW poll encourages the submission of responses for five world regions.

This paper presents a summary of findings in the 1997 poll. Highlights include the following.

The poll medians for 1997 suggest a crude oil price, in 1990 purchasing power, of \$20/b in 2000,\$27/b in 2010 and $\$ 28 / b$ in 2020. Unlike for 2000 and 2010, the 2020 figure diverges considerably from that of the 1996 poll, which registered $\$ 39 / b$.
\end{abstract}

(continued overleaf) 
The author is Senior Scientist, Environmentally Compatible Energy Strategies Project, at the International Institute for Applied Systems Analysis, in Laxenburg, Austria. He is also Co-Director of the International Energy Workshop.

\section{Abstract - continued}

Eastern Europe and the former Soviet Union are not expected to be major global oil exporters until 2010 at least, while China will become a net importer in 2000. OPEC will meet about half global demand by 2020.

World primary energy consumption is expected to increase from 8,500 mtoe in 1990 to 13,000 mtoe in 2020. In this period, oil will lose almost seven percentage points of market share, while natural gas will almost double its absolute contribution. OPEC's natural gas exports are projected to rise from 55 mtoe in 1990 to 300 mtoe in 2020.

Finally, the paper compares different projections for decarbonisation, that is, the decline rates of the carbon intensity of GDP and of primary energy supply. It notes that, according to business-as-usual projections, the OECD is way off target in meeting the emissions-reductions goals of the United Nations Framework Convention on Climate Change. 

HIS PAPER IS THE latest instalment in a series published in the OPEC Review describing the activities of the International Energy Workshop (IEW). The IEW consists of a network of analysts from across the world concerned with international energy issues. It is organised jointly by Stanford University, in the United States of America, and the International Institute for Applied Systems Analysis, in Austria. Since 1981, the IEW has been organising an ongoing poll of projections of crude oil prices, economic growth, primary energy consumption and production, the energy trade and, beginning in the early 1990s, energy-related carbon emissions. The poll results are published regularly (the most recent publication is Manne and Schrattenholzer, 1997), reproducing all responses with a publication date not older than three years and summarising the responses for major world regions as histograms.

For maximum comparability, projections submitted with the original IEW poll form are for the years 1990 through 2020 in ten-year steps. Recently, the two periods, 2050 and 2100, were added, so as to provide an appropriate time-frame for the scenarios addressing the climate change issue. Geographical standardisation is achieved by encouraging poll respondents to submit poll results for the following world regions: Eastern Europe and the former Soviet Union (EEFSU), China, the OECD, OPEC and non-OPEC developing countries (NODC). Together, these five regions cover the entire world. Also, global scenario results are collected, of course, as are results for other major countries and world regions. The 1997 poll edition (Manne and Schrattenholzer, 1997) contains 158 individual responses, which were received from 49 participating organisations who submitted the results of 68 scenarios.

The 1997 IEW poll edition provides the basis for the presentation in this article. The fields that have been selected for this analysis are the oil price, the oil trade, the gas trade, the global primary energy mix and carbon emissions.

\section{Oil price projections}

Expectations concerning the future development of international oil prices have been the most volatile of all the items covered in the IEW poll. Following the two major price rises between 1974 and 1980, projections in the early 1980s reflected expectations of continuing increases. According to the median projections at the first IEW meeting in 1981, today's price would be in the neighbourhood of US $\$ 100$ per barrel (figure 1).

In tandem with the fall in oil prices in the 1980s, poll medians declined precipitously during that decade. Since 1990 , projections have begun to stabilise, again reflecting developments in that period. During the Middle East crisis of 1990/91, we saw a short-lived increase in current prices and slightly higher projections in the poll. After 'forgetting' the crisis, recent projections have narrowed considerably for the years 2000 and 2010. The poll medians of 1996 and 1997 for the year 2000 lie between $\$ 19$ and $\$ 20$ per barrel. Since the IEW Poll measures oil prices in 1990 purchasing power, this means approximately $\$ 24 / \mathrm{b}$ at today's currency value. For 2010, the medians of the 1996 and 1997 projections are still close together, at $\$ 25 / b$ 


\section{Figure 1}

Actual crude oil prices 1970-96 and selected IEW poll medians 1981-97 $1990 \$ 1 b$

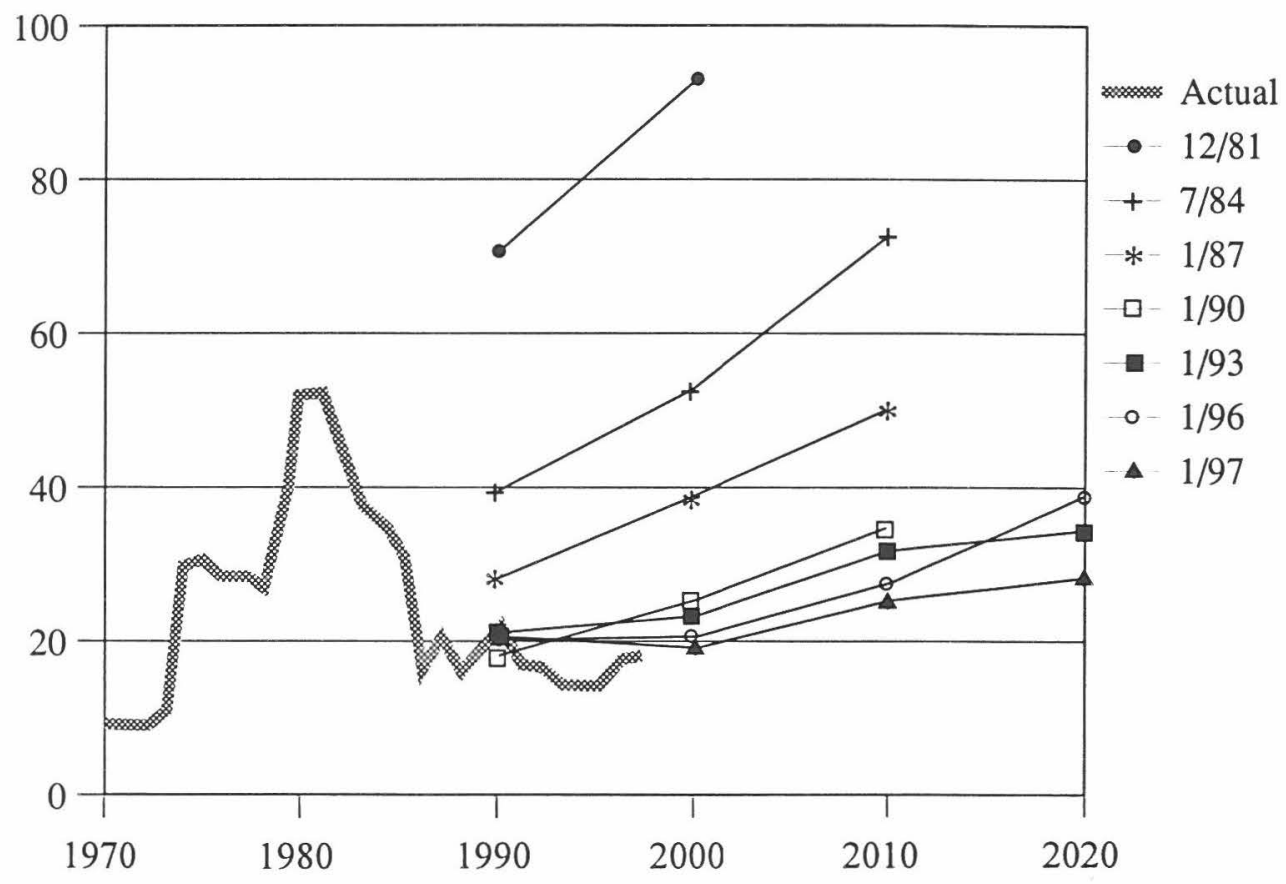

and $\$ 27 / \mathrm{b}$. Only in 2020 is there considerable divergence, that is $\$ 39 / \mathrm{b}$ (1996 poll) and $\$ 28 / \mathrm{b}$ (1997 poll). These two values correspond to average annual growth rates between 2000 and 2020 of 3.3 and 1.7 per cent per year.

The development of the median oil price projections seems consistent with the assumption of Hotelling's Rule guiding the mainstream of price projections. According to this rule, the price of an exhaustible resource tends to rise at a rate equal to the real interest rate. Among the conditions on which the 'rule' is based is one requiring an ideal situation of competitive markets. It is, therefore, not obvious that it even applies in a strict theoretical sense to oil markets. The 'rule' is enormously plausible, however, because it postulates the indifference of resourceowners between producing their resource or borrowing money. The absence of better guidelines might thus be responsible for this consistency with IEW Poll medians.

The median of any sample may be its most informative single descriptor, but it says nothing about extreme values or even the spread of all projections. A measure of the latter is the standard deviation. Assuming a normal distribution, an interval that is two standard variations wide and centred around the mean covers approximately two-thirds of the data points, poll responses in our case. 
Figure 2

Ranges of oil price projections, IEW poll 1997

1990 US \$

$A A G R \%$

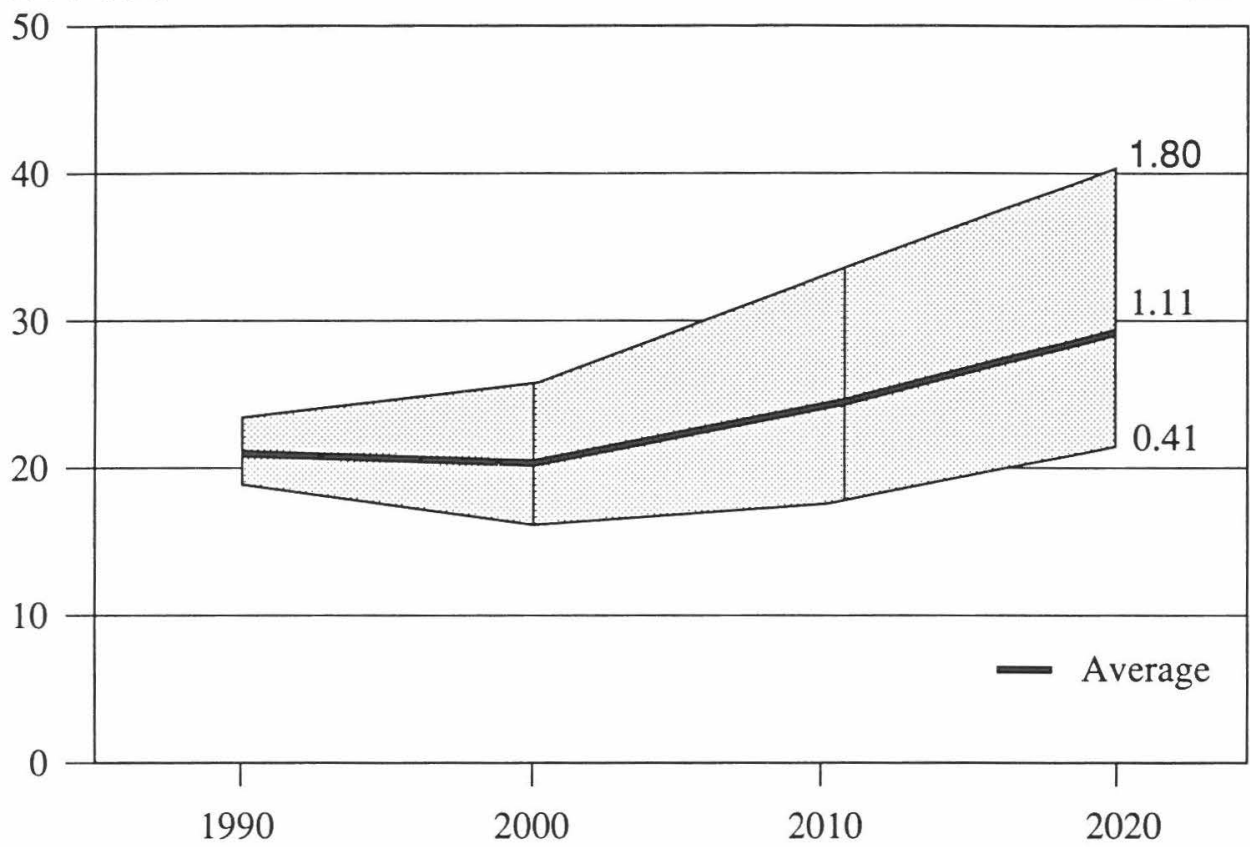

Figure 2 shows the ranges of projections contributing to the 1997 poll. The first thing to note is the comparatively wide range for the 1990 price, which ought to be unambiguous, because it is history. It just so happened, however, that 1990 was a year with unusually high variations in price, as already pointed out. One part of the differences in price projections is therefore explained by the ambiguity of the 1990 base value. Average annual growth rates between 1990 and 2020 have thus been calculated separately for the upper and lower ends of the range, as well as for the averages. These growth rates, expressed as average annual percentages, are $1.80,0.41$ and 1.11 respectively. Expressed in statistical language, this result means that approximately two-thirds of the poll respondents expect an absolute oil price of between $\$ 21.4 / \mathrm{b}$ and $\$ 40.2 / \mathrm{b}$ ('90) in the year 2020. In today's money, this is approximately $\$ 26 / \mathrm{b}$ and $\$ 49 / \mathrm{b}$.

\section{Oil demand, supply and trade}

Median projections of the quantities of crude oil traded at these prices are shown in figure 3.

As the medians reported for different regions can easily be based on different poll responses, they do not necessarily balance the oil trade on a global level in any 
Figure 3

World regional exports of crude oil, IEW poll '97 medians

billion tons of oil equivalent

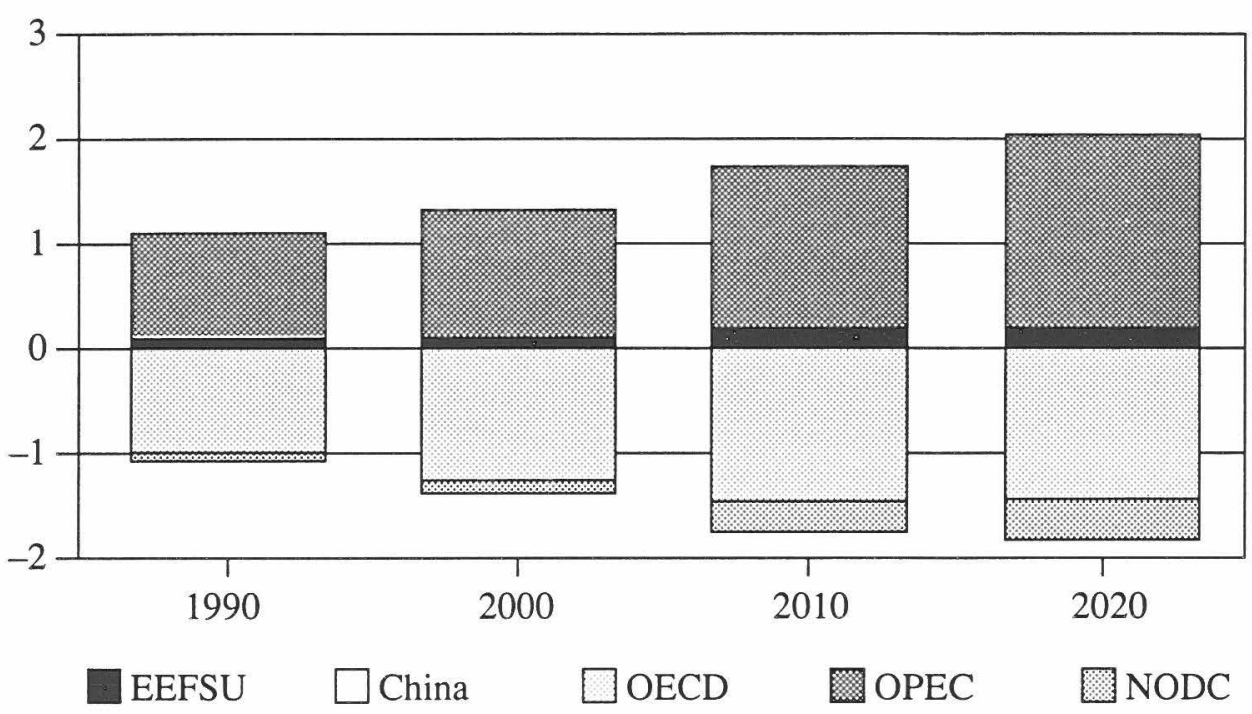

Figure 4

Global primary energy supply, 1990-2020 (IEW '97)

mtoe

mioe

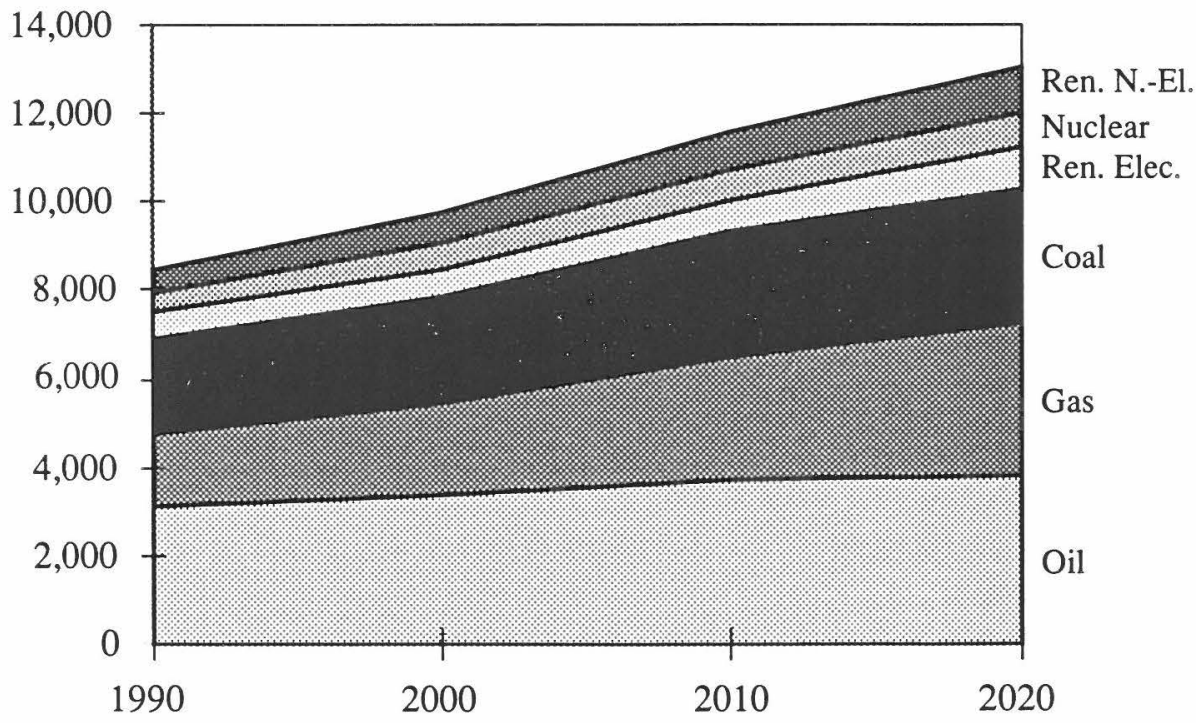


period. However, the natural uncertainty behind the projections is much better reflected in balances that do not add up, than in an artificial preciseness that eliminates all imbalances. In the three periods 1990, 2000 and 2010, these imbalances are - maybe surprisingly - below one per cent of the median projections of global oil consumption. Only in 2020 does the imbalance come near to ten per cent of total consumption, as a surplus.

Analyzing the global oil trade picture, we find that, until 2010 at least, EEFSU is not expected to be a major contributor to global oil exports. Reflecting developments that have already set in, China is projected to become a net importer of oil beginning in 2000, after having been a net exporter in 1990. By 2020, China is projected to import more than 100 million tons of oil equivalent (mtoe) per year (approximately two million barrels per day). Relative to total global oil consumption (not shown in figure 3), the share of traded oil increases from 35 per cent in 1990 to approximately 50 per cent in 2020. OPEC's share of the global oil trade is dominant throughout the time horizon considered here - by 2020, approximately half the global oil demand is supplied by OPEC exports. On the import side, NODC in 1990 imports one-tenth of what the OECD imports. This relation changes significantly by 2020 , when NODC imports are projected to reach almost 50 per cent of OECD imports.

\section{Global primary energy mix}

Between 1990 and 2020, global primary energy consumption is projected to increase from 8,500 mtoe in 1990 to 13,000 mtoe in 2020 (figure 4). On average, this means annual growth of 1.4 per cent.

In terms of the relative contributions of the primary energy-carriers considered in the IEW poll, the biggest changes are expected for oil and gas. Between 1990 and 2020, oil loses almost seven percentage points. Most of the gap left by this relative decrease is filled by natural gas, which almost doubles its absolute contribution in these 30 years. Along with the rise in gas consumption there is increased importance of internationally traded natural gas. Not counting trade within the IEW world regions (and therefore ignoring trade within EEFSU), the share of natural gas that is traded between the IEW world regions grows from 6.3 per cent in 1990 to more than 12 per cent of global natural gas consumption in 2020. OPEC's natural gas exports are expected to increase from 55 mtoe to almost 300 mtoe during this period. This is almost a sixfold increase, from $1.1 \mathrm{mboe} / \mathrm{d}$ to $6 \mathrm{mboe} / \mathrm{d}$, in 30 years.

\section{Carbon emissions}

In 1992, the year of the Earth Summit held in Rio de Janeiro, the IEW poll began to include carbon emissions. The new item on the poll form was introduced to measure the energy-related greenhouse gas (GHG) emissions in a given scenario. In 1997, the IEW collaborated with the Energy Modeling Forum's study EMF-14 on 'Integrated Assessment of Climate Change'. As a consequence, the EMF 
Figure 5

Average annual growth rates of global GDP, total primary energy consumption and carbon emissions, 1990-2050 (upper graph) and 1990-2100 (lower graph), IEW' 97 poll

$\%$ year
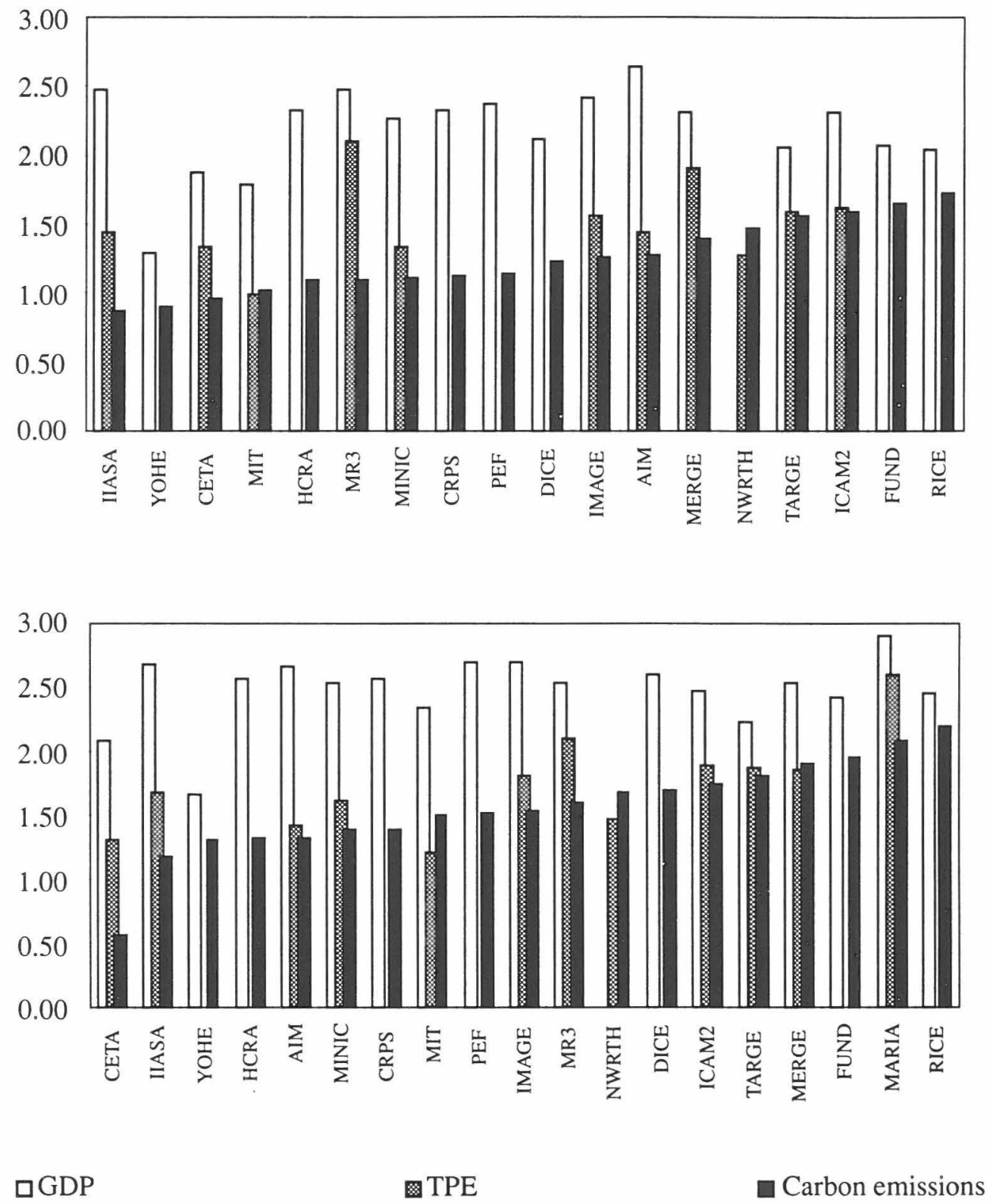
permitted the 1997 poll to include long-term scenarios, i.e. scenarios with the year 2100 as a time horizon. Following the IEW style of focusing on 'business-as-usual' scenarios, only reference cases - and no 'policy' or 'GHG reduction' scenarios were included in the poll.

Summarising the projections of global GHG emissions and their determining factors, figure 5 depicts long-term average growth rates of GDP, total primary energy consumption and carbon emissions.

The figure is divided into two parts, one with average annual growth rates (AAGRs) for 1990-2050 and the other with rates for 1990-2100. The responses to these items have been sorted by the AAGRs of carbon emissions. Subtracting these from the growth rates of GDP and from those of total primary energy consumption provides measures of 'decarbonisation', that is, the rates of decline of the carbon intensity of GDP and of primary energy supply. Figure 5 does not show any obvious correlation between the projected growth of GDP and that of carbon emissions. The IIASA-WEC projection, for instance, is one of the highest with respect to economic growth and one of the lowest for the increase of carbon emissions. At the other end of the scale is the projection submitted by Nordhaus, which was made with the RICE model (Nordhaus and Yang, 1995). It is difficult to analyze the reasons for the difference between the two projections in detail, because Nordhaus's RICE estimates the carbon intensity of GDP directly, without disaggregating into the energy intensity of GDP and the carbon intensity of primary energy. RICE's carbon intensity is estimated for ten world regions and then aggregated. Over the entire time horizon (1990-2100), the decarbonisation of global GDP in RICE thus proceeds at an average annual rate of 0.3 per cent. This is lower than IIASA-WEC's decarbonisation of total primary energy alone (more than 0.5 per cent per year). Add to this IIASA-WEC's reduction of the overall energy intensity of GDP (slightly higher than one per cent per year) and IIASA-WEC's GDP decarbonises at an average annual rate of 1.6 per cent. IIASA's projection of decarbonisation of GDP is closer to the long-term trend of 1.3 per cent per year (Nakicenovic et al, 1993).

Analyzing the medium-term projections of carbon intensities projected in the IEW poll gives the picture shown in figure 6, showing the carbon intensity of GDP for all poll responses between 1990 and 2020 .

The figure shows that the medium-term projections also expect a continuation of the historical trend of decarbonisation. The median annual decline in the projected carbon intensities of GDP is 1.45 per cent between 1990 and 2020. Owing to the large variety of countries and regions underlying the graph, the range of these projections (in the above sense, that is, representing approximately twothirds of the responses) lies between average declines of 0.48 per cent and 2.42 per cent per year.

For carbon emissions in the OECD, the poll results permit a comparison between the goals of the Third Conference of the Parties to the United Nations Framework Convention on Climate Change (COP3/UNFCCC) in Kyoto and 'business-as-usual' expectations. Assuming an unchanged goal of stabilising greenhouse gas emissions by the OECD countries in the year 2000 (relative to 
Figure 6

Carbon intensity of GDP, all regions

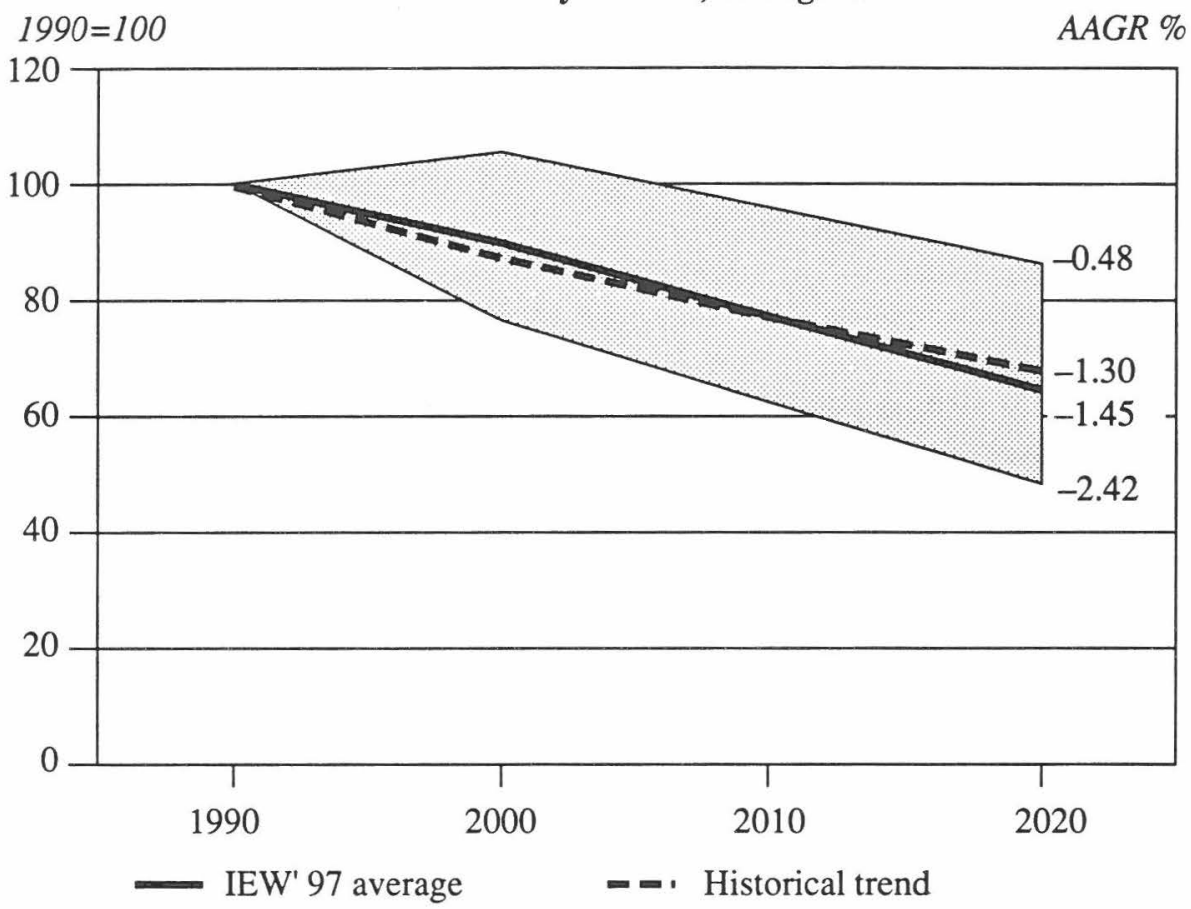

Figure 7

OECD carbon emissions, IEW Poll '97 averages, ranges and target million tons of carbon

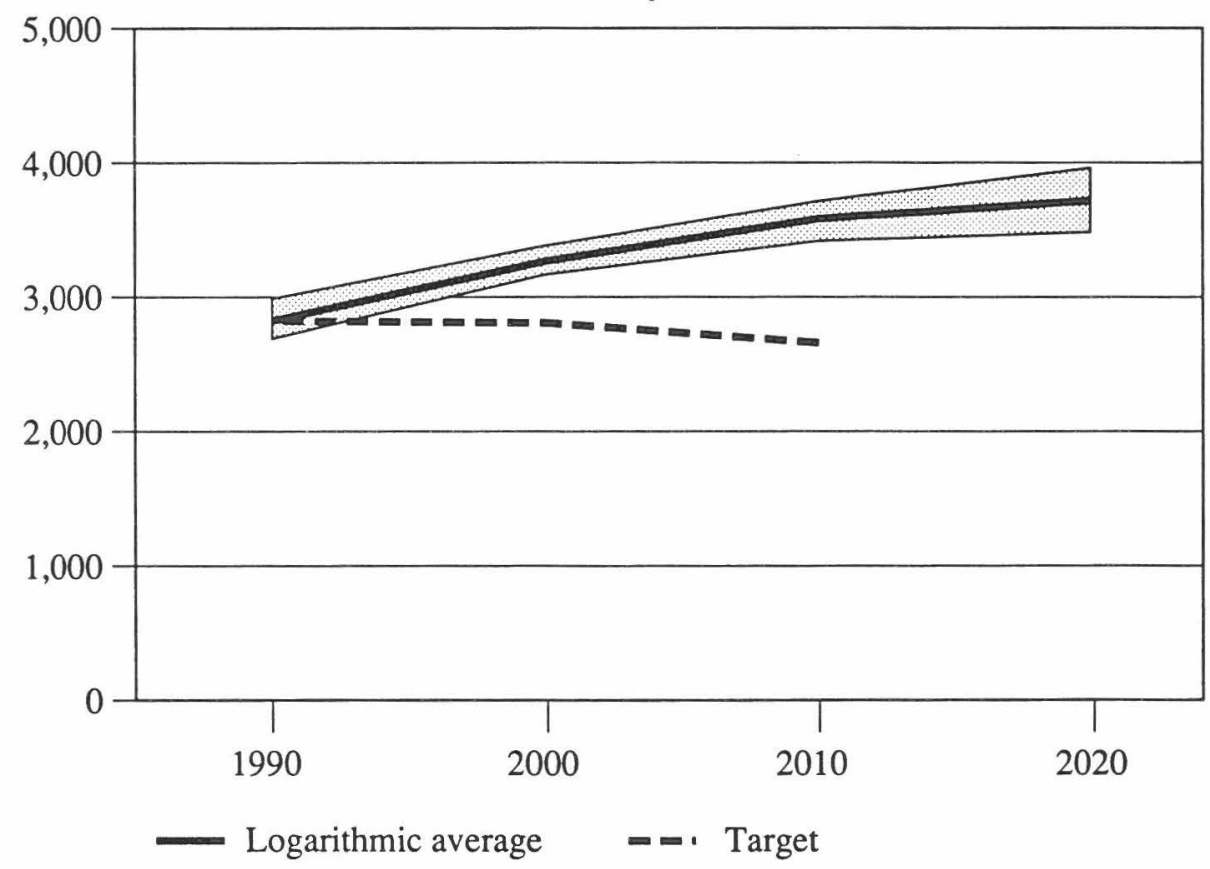


1990) and a six per cent reduction in 2010 (Bolin, 1998), the poll projections show that the UNFCCC goals seem far off present trends (figure 7).

In the draft protocol of the Kyoto conference, six greenhouse gases are covered. The IEW poll covers only one of them, carbon dioxide, but the increase in this gas alone now accounts for about 70 per cent of the enhanced greenhouse effect (Bolin, op cit); therefore, the picture shown in figure 7 should be at least representative of the divergence between the target and the inertia of the system displayed in current expectations. Presumably, governments will now work hard to find out whether the political costs of bridging this gap will be acceptable before they will actually ratify the Kyoto agreement.

\section{Concluding remarks}

The IEW poll results are a collection of projections of the energy system's development and its major determinants. As such, their value is primarily phenomenological, as the projections are not always accompanied by detailed explanations.

It is hoped that this article shows the usefulness of the poll for analyses that take the mainstream of energy projections as a starting point. Over time, the series of poll editions also provides a record of forecasting. It is probably easy to look at the dynamics of oil price projections as a failure on the side of the forecasters, but it would seem more useful to go back to the projections that turned out to be far off the actual developments. Unfortunately, scenarios are not always accompanied by a discussion of the assumptions that lead to essential scenario features. The EMF is an attempt to encourage just this - the transparent presentation of the path that leads from assumptions to results. In this spirit, the IEW has again joined forces with the EMF, and the 1998 annual IEW meeting will be held jointly, as in 1997. For more information on the meeting, please contact the author at IIASA (Schlossplatz 1, A-2361 Laxenburg, Austria). 


\section{References}

Bolin, B., 1998, "The Kyoto negotiations on climate change: a science perspective," in Science 279:330--331.

International Institute for Applied Systems Analysis and World Energy Council, (IIASAWEC), 1995, Global Energy Perspectives to 2050 and Beyond, World Energy Council, London, UK.

Manne, A., and Schrattenholzer, L., 1997, International Energy Workshop: Summary of Poll Responses, International Institute for Applied Systems Analysis, Laxenburg, Austria, and Stanford University.

Nakicenovic, N., Grübler, A., Inaba, A., Messner, A., Nilsson, S., Nishimura, Y., Rogner, H.-H., Schäfer, A., Schrattenholzer, L., Strubegger, M., Swisher, J., Victor, D., and Wilson, D., 1993, Long-term strategies for mitigating global warming, special issue of Energy, The International Journal 18(5): 401-609.

Nordhaus, W.D., and Yang, Z., 1996. RICE: a regional dynamic general equilibrium model of optimal climate change policy, Yale University, New Haven, CT, USA. 